\title{
Perception of Air Pollution in the Jinchuan Mining Area, China: A Structural Equation Modeling Approach
}

\author{
Zhengtao $\mathrm{Li}^{1,2, *}$, Henk Folmer ${ }^{2,3}$ and Jianhong Xue ${ }^{3}$ \\ 1 Department of Industry and Economics, School of Economics and Finance, Xi'an Jiaotong University, No. 74, \\ the West Yanta Road, Xi'an 710061, China \\ 2 Department of Economic Geography, Faculty of Spatial Sciences, University of Groningen, Landleven1, \\ Groningen 9747 AD, The Netherlands; h.folmer@rug.nl \\ 3 Department of Agricultural Economics, College of Economics and Management, \\ Northwest A \& F University, 3 Taicheng Road, Yangling 712100, China; xuej@nwsuaf.edu.cn \\ * Correspondence: zhengtao_li@126.com; Tel.: +86-158-0292-3770
}

Academic Editor: Kim Natasha Dirks

Received: 20 June 2016; Accepted: 27 June 2016; Published: 21 July 2016

\begin{abstract}
Studies on the perception of air pollution in China are very limited. The aim of this paper is to help to fill this gap by analyzing a cross-sectional dataset of 759 residents of the Jinchuan mining area, Gansu Province, China. The estimations suggest that perception of air pollution is two-dimensional. The first dimension is the perceived intensity of air pollution and the second is the perceived hazardousness of the pollutants. Both dimensions are influenced by environmental knowledge. Perceived intensity is furthermore influenced by socio-economic status and proximity to the pollution source; perceived hazardousness is influenced by socio-economic status, family health experience, family size and proximity to the pollution source. There are no reverse effects from perception on environmental knowledge. The main conclusion is that virtually all Jinchuan residents perceive high intensity and hazardousness of air pollution despite the fact that public information on air pollution and its health impacts is classified to a great extent. It is suggested that, to assist the residents to take appropriate preventive action, the local government should develop counseling and educational campaigns and institutionalize disclosure of air quality conditions. These programs should pay special attention to young residents who have limited knowledge of air pollution in the Jinchuan mining area.
\end{abstract}

Keywords: perception of air pollution; environmental knowledge; structural equation model (SEM); latent variable; China

\section{Introduction}

Many studies have shown that air pollution is a major public health concern for a large part of the world's population (see inter alia [1-3]). The adverse health effects of exposure to, especially, particulate matter $(\mathrm{PM})$ and sulfur dioxide $\left(\mathrm{SO}_{2}\right)$, range from respiratory illnesses $[4,5]$ and cardiovascular illnesses [6,7], to lung cancer [8,9] and premature death [10].

The situation in China is worse than in many other parts of the world. Economic development has greatly increased energy consumption, mining, and construction in recent decades $[11,12]$ leading to serious air pollution in many urban, industrial and mining areas. The main air pollutants include nitrogen dioxide $\left(\mathrm{NO}_{2}\right)$, ozone $\left(\mathrm{O}_{3}\right)$, sulfur dioxide $\left(\mathrm{SO}_{2}\right)$ and particulate matter $(\mathrm{PM})[13,14]$.

Jinchuan, which is located in the western province of Gansu, is one of the ten cities with the most serious air pollution in China [15]. It has the largest nickel resource in the country and mining and smelting industries dominate its economy and make a substantial contribution to its development. 
However, the two industries also create serious environmental problems, including industrial solid waste and soil, water and air pollution. The main air pollutants include suspended particles, sulfur dioxide, chlorine gas and carbon dioxide [15-17]. An important question is if, and to what extent, the residents of Jinchuan have adopted their behavior to mitigate the health impacts caused by air pollution (averting behavior) in their home region.

Most studies on averting behavior related to (air) pollution link averting behavior to objective measures of emissions. However, such an approach ignores the fact that averting behavior presupposes contextual knowledge of the pollution in question and related hazards [18-20]. These authors [18-20] argued that not only factual information about pollution is applied in decision making related to averting behavior but also environmental knowledge and perception of the situation. Another important reason to consider perception rather than relying on factual information is that laboratory experiments have frequently indicated that individuals tend to under-estimate high risk events and over-estimate small risk events [21,22].

Analyses of the impacts of perception on behavior usually do not distinguish between perception of the occurrence of pollution and perception of its health risks (which is subjective probability based on an individual's personal judgment and is different from objective probability which is calculated from observed frequencies [23]). The two kinds of perception are usually taken together and the combination is analyzed. However, perception of the probability of suffering from an illness as a result of pollution is different from the perception of pollution per se. There is not an automatic link between perception of the probability of occurrence of pollution and perception of the likelihood to incur an illness [24,25]. In particular, the former is a prerequisite for the latter, which in its turn affects averting behavior aimed at reducing the health risk. Ignoring the difference may lead to loss of information and to biased estimation results. Specifically, an insignificant impact of risk perception on averting behavior could actually be a consequence of a lack of perception of pollution per se $[18,26]$. The distinction between both types of perception is also relevant for educational campaigns aimed at stimulating averting behavior [26]. Meaningful campaigns should target the right kind of perception.

The distinction between perception of pollution as such and perception of the likelihood to incur an illness is especially relevant in the case of a country, such as China, where information about pollution is often not disclosed or not freely available [27]. Chinese citizens who seek information about pollution are often considered "troublemakers" by the Government and corporate officials [28] and only inessential information tends to be disclosed to the public to comply with regulations [29]. Furthermore, the disclosed information may not be entirely accurate in order to mask or falsify actual environmental performance [30]. The above conditions definitely apply to the city of Jinchuan, which is located in a remote area and critically depends on its mining and smelting industries.

Perception of environmental hazards including perceived health risks has become a multi-disciplinary field of research including psychology, economics, geography, health sciences, anthropology and sociology. Studies on the perception of a wide variety of environmental hazards have been undertaken including forest fire [31], drinking water [32], pesticides [33,34], earthquakes [35,36] and nuclear power [37]. Bickerstaff and Walker [1] and Howel et al. [38] focused on the perception of the occurrence of air pollution and [39-41] on the health risk of air pollution. Richardson et al. [42] analyzed the economic health costs of exposure to wildfire smoke and [25] analyzed the interrelations between odorous air pollution levels, perceived pollution, health risk perception, annoyance and health symptoms.

The main objective of this paper is to analyze the determinants of the perception of the intensity and hazardousness of air pollution in the Jinchuan mining area, Gansu Province, China, based on a cross-sectional sample of 759 respondents. It makes the following contributions to the literature: First, a better understanding of the perception of health risks in the Jinchuan mining area which is China's "nickel capital" [15]. Second, it empirically identifies the dimensions of perception of pollution in the study area. Third, it contributes to a better understanding of the effect of people's environmental knowledge on their perception of (air) pollution and vice versa. Fourth, it estimates 
the effects of socio-demographic characteristics on environmental knowledge and perception of air pollution. Finally, it is intended to stimulate of national and local governments to develop counseling and educational campaigns in the short run and air pollution abatement and management programs in the long run.

This paper is organized as follows. Section 2 presents the conceptual model. It defines the endogenous variables perception of air pollution and environmental knowledge, specifies the interdependencies among the endogenous variables mutually as well as the impacts of the exogenous variables on the endogenous. Section 3 describes the survey and sampling method and the econometric methodology (SEM). Section 4 presents the empirical results. Section 5 discusses the study's findings and Section 6 presents the conclusions.

\section{Conceptual Model}

In this section, the conceptual model (in the literature also denoted as the theoretical model) is presented. It consists of the theoretical definitions of the variables (nomenclature), the rationale for their inclusion in the model, the relationships among the endogenous variables, and the impacts of the exogenous variables on the endogenous variables. The conceptual model thus forms the hypotheses, which are tested in Section 4 (Empirical Results). It is based on a literature review, on consultation with experts on environmental problems-notably air pollution and protection against it in Jinchuan- and on intuition. (See inter alia [43] for details about the conceptual model as a set of hypotheses and its role in empirical analysis.).

Before going into detail, we note that since perception of air pollution is an aspect of the perception of its health risks, the literature review relates to both types of perception, especially because the literature on perception of (air) pollution per se is small.

The Perception of air pollution-Environmental knowledge (PAP-EK) conceptual model is summarized in Figure 1. It contains two endogenous variables, Perception of air pollution (PAP) and Environmental knowledge (EK), and the exogenous variables Age, Proximity to the pollution source, Work environment, Socio-economic status and Family health experience. In Figure 1, an arrow denotes the direction of a hypothesized relationship (impact) between an exogenous and an endogenous variable or between the two endogenous variables. The endogenous variables PAP and EK and their relationships are discussed first. Next, the effects of the exogenous variables, i.e., Socio-economic status, Age, Family size, Family health experience, Proximity to the pollution source and Work environment on PAP and EK, are discussed.

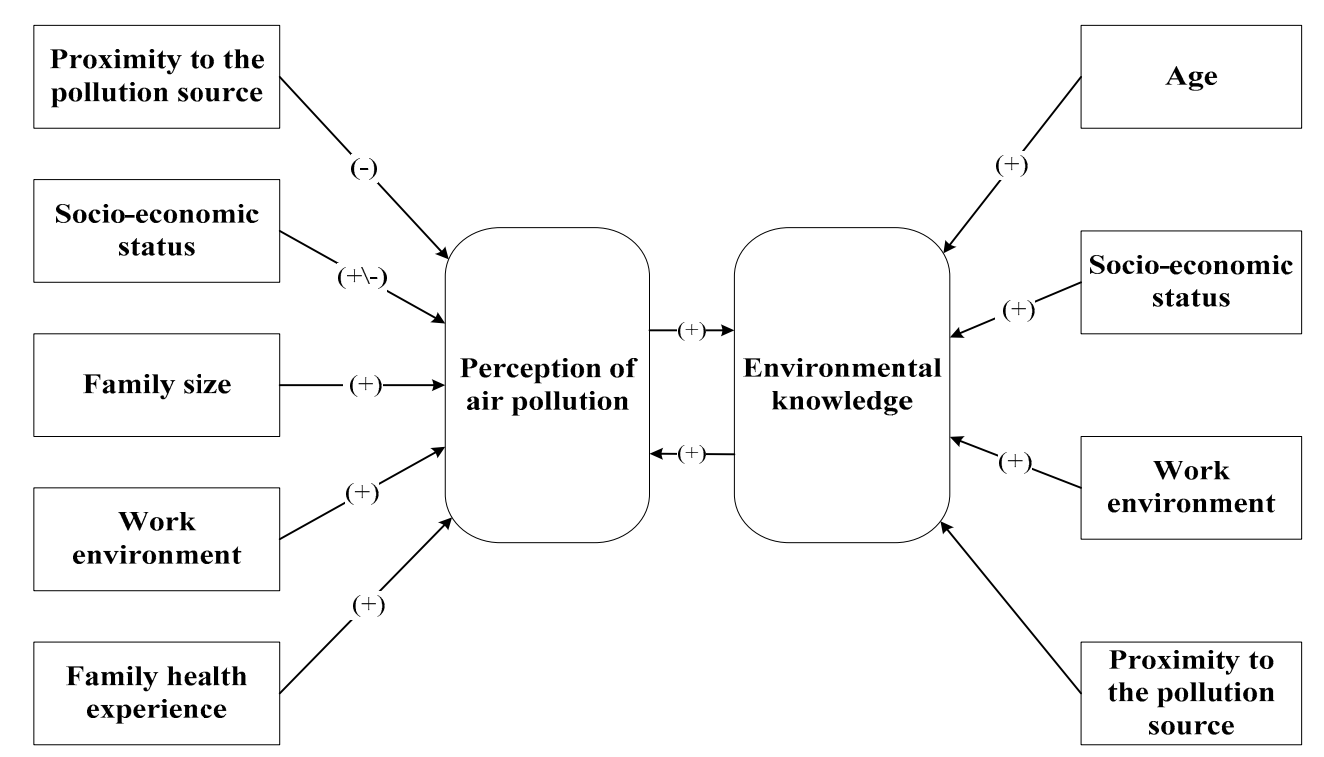

Figure 1. The Perception of air pollution-Environmental knowledge (PAP-EK) model. Note: Within the brackets are the expected signs. 


\subsection{Endogenous Variables}

Perception of air pollution (PAP). The main dependent variable of the PAP-EK model is PAP. Sjöberg et al. [44] defined PAP as the subjective assessment of its intensity and the concern with the consequences of exposure to it. Two dimensions are contained in this definition: (i) perception of intensity of air pollution; and (ii) perception of hazardousness of the pollutants. The first dimension is measured by the question: "What is your perception of the average number of days per week that Jinchuan's air was heavily polluted during the past year?" (PAP1) The second dimension was measured by presenting four major types of health problems related to air pollution to the respondents (PAP2-5). They were asked to indicate to what extent they perceived Jinchuan's air pollution as being responsible for inducing health problems. The four major health problems were respiratory diseases, cardiovascular diseases, lung cancer and death (see Figure 2 for details).

The observed variables are taken as indicators of a latent variable, PAP. Latent variables relate to phenomena that are supposed to exist but cannot be directly observed. The reason is that they are theoretical constructs that do not correspond to anything that can be measured, or that observations of the phenomena concerned are measured with error. Examples of latent variables are welfare, happiness and intelligence. A latent variable is given empirical meaning by way of correspondence statements that link a latent variable to its indicators, which are observed variables. Observed variables such as age, income and education, possess direct empirical meaning. For instance, the latent variable intelligence is given empirical meaning by means of intelligence tests. For further details on latent variables, see amongst others [45-48]. (In this paper, there are three latent variables: PAP, EK and Socio-economic status). As a first step, we assume that all five observed variables are indicators of a single latent variable, PAP.

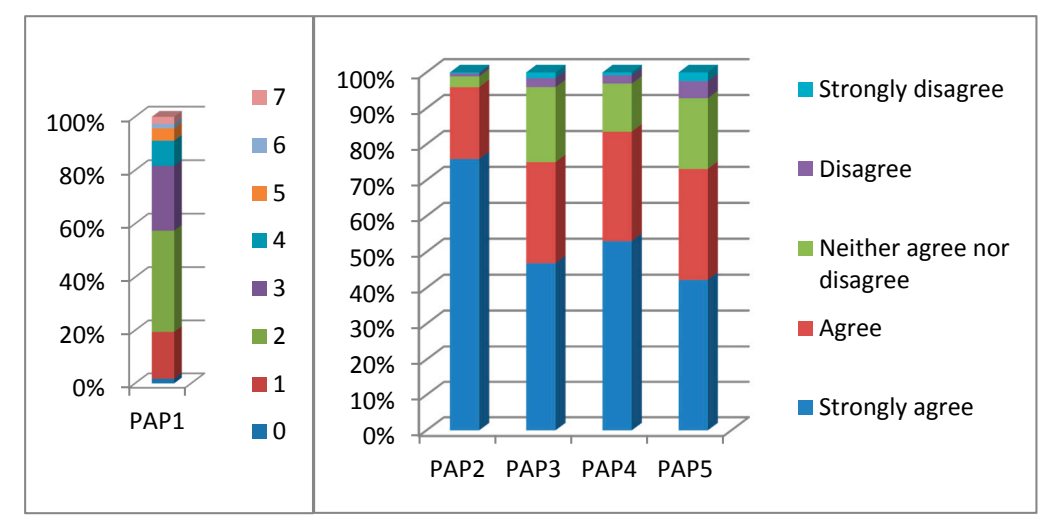

Figure 2. Frequency distribution of the indicators of the Perception of air pollution. Notes: PAP1: How many days a week did you perceive the air in Jinchuan city to be heavily polluted last year? PAP2: Jinchuan's air pollution increases the possibility of suffering from respiratory illnesses. PAP3: Jinchuan's air pollution increases the possibility of suffering from cardiovascular illnesses. PAP4: Jinchuan's air pollution increases the possibility of suffering from lung cancer. PAP5: Jinchuan's air pollution increases the possibility of suffering from death. Source: Author's survey

Environmental knowledge (EK). Berkes et al. [49] defined EK as one's body of knowledge of the interdependency between human society and its natural environment. Based on the air quality conditions in Jinchuan, the respondents' knowledge of air pollution was measured by means of eight items. The first four are related to general environmental issues and their causes, and the remainder are related to the main air pollutants in the area (see Figure 3). Note that the notion of environmental knowledge is related to, though different from, notions such as environmental awareness and beliefs. De Lavega [50] pointed out that environmental awareness is the concern and sensitivity towards the environment and its problems. Madsen [51] showed that awareness is a driving force of knowledge accumulation. The difference between knowledge and belief depends on the degree of uncertainty. When uncertainty diminishes, belief gradually turns into knowledge [52,53]. 


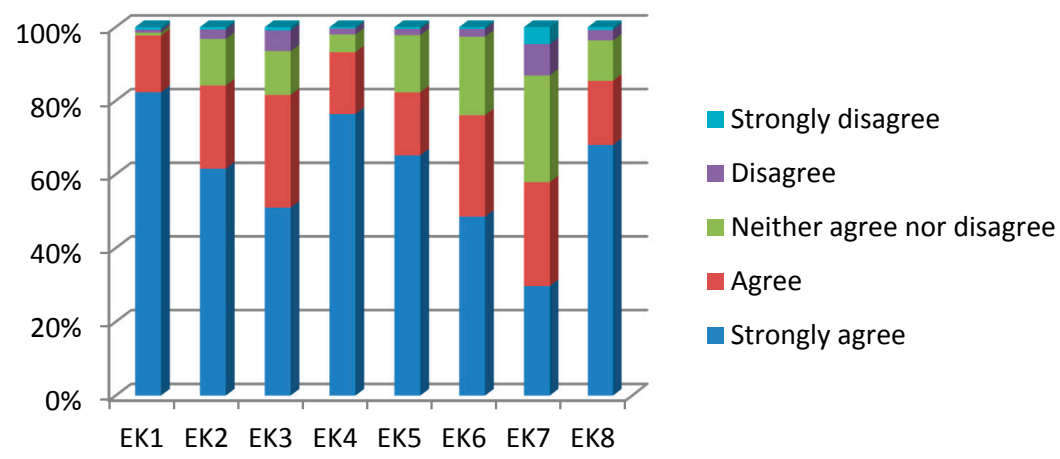

Figure 3. Frequency distribution of the indicators of Environmental knowledge. Notes: EK1: Jinchuan suffers from air pollution. EK2: Jinchuan suffers from industrial solid waste. EK3: Jinchuan suffers from water pollution. EK4: Environmental issues in Jinchuan are mainly caused by local industrial activities. EK5: Sulfur dioxide is one of the main air pollutants of Jinchuan. EK6: Suspended particles is one of the main air pollutants of Jinchuan. EK7: Carbon dioxide is one of the main air pollutants of Jinchuan. EK8: Chlorine gas is one of the main air pollutants of Jinchuan. Source: Author's survey

PAP and EK are assumed to interact. First, as explained by [54]. EK is an important determinant of PAP. A positive impact is expected: better knowledge improves perception. Evidence for this hypothesis can be derived from [32] who found that better knowledge of a pesticide increased the perception of the risk following exposure to it. Similar results were found by [55,56]. Secondly, PAP is assumed to stimulate EK. A positive effect is expected: the more pollution one perceives, the more knowledge of it will be collected $[57,58]$.

Note that the interaction between PAP and EK may be subject to self-confirmation bias, i.e., the tendency that people look for evidence that confirms their beliefs and overlook the evidence that goes against them [59]. For instance, [60] conducted research on tuberculosis in the UK and found that perception of tuberculosis induced people to look more for information that confirmed their beliefs than for information that denied them. If there is self-confirmation bias, people who perceive air pollution will: (i) expand their environmental knowledge; and (ii) select environmental knowledge that confirms their beliefs and overlook evidence against them. An insignificant impact of PAP on EK knowledge is evidence against self-confirmation bias. The issue is discussed further in Section 4.2.

\subsection{Exogenous Variables}

Age (AGE). Age is assumed to have a positive impact on EK. The rationale is that older people have lived longer in Jinchuan than younger people and thus have more experience with, and better knowledge of, Jinchuan's mining and smelting industries. Support for the hypothesis can be derived from [61,62]. An indirect impact of Age on PAP—via EK-is hypothesized.

Proximity to the pollution source (PPS). PPS is assumed to have a direct impact on EK. The number of studies on the relationship between PPS (smelting plants) and EK is very limited. An exception is [63], who studied noise pollution in Zahedan, Iran. The author did not find evidence of differences in peoples' knowledge based on distance from the pollution source. Given the weak evidence from the literature, an expected sign is not specified.

A negative impact of PPS on PAP is postulated because respondents who live further away from the smelting plants are less exposed than those who live nearby. Evidence can be derived from $[1,38]$. Three categories are distinguished:

(1) SAP (Nearby smelting plants, serious air pollution);

(2) MAP (medium air pollution); and

(3) LAP (far away from pollution source, light air pollution).

Work environment (WE). A positive impact of WE on EK is assumed. Since it is the source of Jinchuan's environmental issues, people working in the Jinchuan Mining Company (JMC) are expected 
to have better knowledge of Jinchuan's environmental issues than non-JMC individuals. In particular, JMC employees, especially miners and smelter workers, are expected to know more about the input and output of the smelting process than non-JMC individuals. Evidence for the hypothesis can be drawn from $[32,64]$.

Work environment is also hypothesized to have an impact on PAP. That is, the JMC employees, especially the ones who work in the mine or smelter, are expected to have higher perception levels than non-JMC individuals. The rationale is that their work places are the most seriously polluted. Support for the hypothesis can be derived from $[18,65]$. Three WE classes are distinguished:

(1) MS (miners and smelter workers of JMC);

(2) NMS (people who are JMC employees, but not miners or smelter workers); and

(3) NMC (non-JMC individuals) which is the base case.

Socio-economic status (SES). SES is commonly conceptualized as an individual's standing in society [66]. It is measured here by means of the observed variables Educational Attainment (EDU) and Household Net Income (IN). SES is assumed to positively impact EK. This hypothesis is supported by [67-69]. A direct impact of SES on the PAP is assumed.

The literature is ambiguous about the signs of the impact. A positive relationship was found by [70-72]. On the other hand, [73] analyzed data from a national survey in Canada and found that SES was negatively correlated with perception of health risk. Because of the opposing views, no expected sign is a priori assigned. EDU is measured as the highest degree obtained and IN as after tax household income (see Table 1 for details).

Table 1. Descriptive statistics for the observed exogenous variables.

\begin{tabular}{|c|c|c|c|c|c|}
\hline \multicolumn{2}{|l|}{ Variables } & Min & Max & Mean & S.D \\
\hline \multicolumn{2}{|l|}{ Age (AGE) } & 21 & 78 & 44.11 & 11.4 \\
\hline \multicolumn{2}{|c|}{ Family Size (FS) } & 1 & 6 & 2.95 & 0.78 \\
\hline \multicolumn{2}{|c|}{ Family health experience (FHE) } & 0 & 1 & 0.33 & 0.48 \\
\hline Highest Level of Education (EDU) & Absolute & Percentage & $\begin{array}{l}\text { Household Net } \\
\text { Income (CNY per } \\
\text { Month) (IN) }\end{array}$ & Absolute & Percentage \\
\hline Primary school & 48 & $(6.00 \%)$ & $1000-2000$ & 36 & $(4.70 \%)$ \\
\hline Middle school & 179 & $(23.60 \%)$ & $2000-3000$ & 116 & $(15.30 \%)$ \\
\hline High school & 192 & $(25.30 \%)$ & $3000-4000$ & 139 & $(18.30 \%)$ \\
\hline Vocational school & 192 & $(25.30 \%)$ & $4000-5000$ & 145 & $(19.10 \%)$ \\
\hline Bachelor's degree & 145 & $(19.10 \%)$ & $5000-6000$ & 159 & $(20.90 \%)$ \\
\hline Master's degree & 3 & $(0.40 \%)$ & $6000-7000$ & 99 & $(13.00 \%)$ \\
\hline \multicolumn{3}{|c|}{ Proximity to the Pollution Source (PPS) } & $7000-8000$ & 28 & $(3.70 \%)$ \\
\hline $\begin{array}{l}\text { Nearby smelting plants, } \\
\text { severe air pollution (SAP) }\end{array}$ & 225 & $(29.60 \%)$ & $\begin{array}{c}8000-9000 \\
9000-10,000\end{array}$ & $\begin{array}{c}14 \\
8\end{array}$ & $\begin{array}{l}(1.80 \%) \\
(1.10 \%)\end{array}$ \\
\hline $\begin{array}{c}\text { Medium air pollution } \\
\text { (MAP) }\end{array}$ & 226 & $(29.80 \%)$ & More than 10,000 & 15 & $(2.00 \%)$ \\
\hline $\begin{array}{l}\text { Far away from smelting } \\
\text { plants, light air pollution } \\
\text { (LAP, reference case) }\end{array}$ & 308 & $(40.60 \%)$ & & & \\
\hline \multicolumn{3}{|c|}{ Work Environment (WE) } & & & \\
\hline $\begin{array}{l}\text { Non-JMC individual } \\
\text { (reference case) }\end{array}$ & 452 & $(59.55 \%)$ & & & \\
\hline $\begin{array}{l}\text { Miners and smelters } \\
\text { worker of JMC (MS) }\end{array}$ & 138 & $(18.18 \%)$ & & & \\
\hline $\begin{array}{l}\text { JMC employee, but not } \\
\text { miner or smelter worker } \\
\text { (NMS) }\end{array}$ & 169 & $(22.27 \%)$ & & & \\
\hline
\end{tabular}

Notes: Family size (FS): number of family members living in the same house; Family Health experience (FHE): 1 if the respondent or one or more of their family members has been hospitalized for cardiovascular (e.g., hypertension, heart attack, chest pain, arrhythmia and myocardial infraction) or respiratory diseases (e.g., upper respiratory tract infection, bronchitis, pneumonia, asthma, and lung cancer), 0 otherwise. Source: Author's survey. 
Family size (FS). A positive impact of FS on PAP is assumed, because in larger families more people are exposed than in smaller families. This assumption is supported by [72,74]. No direct impact of FS on EK is assumed. FS is defined as the number of family members who live in the same house.

Family health experience (FHE). FHE is assumed to have a positive impact on PAP. This assumption is supported by [38,75]. An indirect impact of FHE on EK-via PAP-is hypothesized. FHE is measured by means of a dichotomous variable which takes the value 1 if the respondent, or one or more of their family members, has been hospitalized for cardiovascular or respiratory disease.

\section{Methods}

\subsection{Sampling and Data Collection}

A survey was conducted in July and August 2012 in the Jinchuan mining area. In order to capture air pollution characteristics from the Jinchuan mining area, stratified sampling (see [76] for details) was applied based on the degree of pollution (severely, moderately and lightly polluted areas) which corresponds to the distance to the pollution source (smelting plants). Within each stratum, households were randomly sampled proportional to the stratum size relative to the population size. Per hundred households, one to two households were selected. Interviewees, who were permanent Jinchuan residents with Jinchuan "Hukou", were family heads, usually the husbands. (A Hukou is a record in China's household registration system. It identifies a person as a resident of a village, town or city and includes information such as name, parents, spouse, and date of birth. A Hukou serves as a domestic passport and regulates population distribution, rural-to-urban migration and eligibility to public services.) The minimum age for respondent in the survey was twenty-one years; no upper age limit was imposed. The sample consisted of 800 family heads.

The questionnaire was administered through face-to-face interviews. Interviewers were students of Gansu Non-ferrous Metallurgy College in Jinchuan, who were familiar with environmental issues in Jinchuan and had mastered the local language. To reduce interviewer variability impact on information gathering, all interviewers underwent a training program to ensure that they had the skills and knowledge to correctly carry out interviews. The questionnaire contained questions about a respondent's environmental knowledge, perception of air pollution and socio-demographic characteristics. A pilot survey was conducted to test each question and to revise it, if necessary. Each interview took approximately an hour.

\subsection{Structural Equation Modeling (SEM)}

The conceptual PAP-EK model is estimated as a structural equation model with latent variables (SEM) for the following reasons. First, the conceptual model contains two interacting endogenous variables (see Figure 1 and Equation (4) below). In particular, Figure 1 hypothesizes interaction between EK and PAP. To model interacting endogenous variables, simultaneous-equations models are required (see inter alia $[77,78])$. Secondly, the model contains both latent and observed variables. Both types of variables can be simultaneously handled by SEM because it is made up of: (i) two measurement models that represent the correspondence statement between the latent variables and their indicators; and (ii) a structural model that specifies the relationships between the latent variables (some or all of which may be identical to their observed indicators (see [77] and the references therein). (It is possible to combine the two measurement models, see [78]. Furthermore, means and intercepts can be included in the system. However, they are not included in this paper because all variables are standardized.)

Equation (1) is the structural model:

$$
\eta=B \eta+\Gamma \xi+\zeta
$$

where $\eta$ and $\xi$ are the $(m \times 1)$ and $(n \times 1)$ vectors of latent endogenous and exogenous variables, respectively. The $(\mathrm{m} \times \mathrm{m})$ matrix contains the structural relationships among the latent endogenous 
variables. The impacts of the exogenous latent variables on the endogenous latent variables are given by $\Gamma$, which is an $(m \times n)$ matrix. $\zeta$ is a random $(m \times 1)$ vector of errors with covariance matrix $\mathbf{\Psi}(\boldsymbol{m} \times \boldsymbol{m})$. The covariance matrix of $\xi$ is $\boldsymbol{\Phi}(n \times \boldsymbol{n})$.

Equations (2) and (3) are the measurement models that present the relationships between the latent variables and their indicators (correspondence statements):

$$
\begin{aligned}
& y=\Lambda_{y} \eta+\epsilon \\
& x=\Lambda_{x} \xi+\delta
\end{aligned}
$$

where $y$ and $x$ are the $(\mathrm{p} \times 1)$ and $(\mathrm{q} \times 1)$ vectors of observed endogenous and exogenous variables, respectively. The $(\mathrm{p} \times \mathrm{m})$ and $(\mathrm{q} \times \mathrm{n})$ matrices $\Lambda_{y}$ and $\boldsymbol{\Lambda}_{x}$ specify the relationships (loadings) between $y$ and $x$ and their corresponding latent variables $\eta$ and $\xi$, respectively. $\varepsilon$ and ffi are the measurement errors with covariance matrices $\boldsymbol{\Theta}_{\varepsilon}(\boldsymbol{p} \times \boldsymbol{p})$ and $\boldsymbol{\Theta}_{\delta}(\boldsymbol{q} \times \boldsymbol{q})$, respectively. (Note that a directly observed variable can be straightforwardly handled in the SEM framework by defining it identical to its corresponding latent variable and specifying an identity relationship in the measurement model.)

Estimation can be done by means of the software packages Lisrel 8, OpenMx (in R), AMOS and Mplus. Lisrel 8, applied in this paper, is probably best known (for details, see [77]). Lisrel 8 also provides information on identification and various test statistics including overall goodness of fit statistics, $\mathrm{z}$-statistics for each coefficient and $R^{2} \mathrm{~s}$ for the measurement model equations and the structural equations. Moreover, it provides modification indices that can be used to improve the model fit by freeing incorrectly constrained or fixed parameters.

\section{Empirical Results}

\subsection{Descriptive Statistics}

The number of dropout as a result of incomplete questionnaires was 41 (5.12 percent) which gives a dataset of 759 observations. There was no evidence of non-random drop out.

Descriptive statistics are presented in Table 1, and Figures 2 and 3. The distribution of the socio-economic characteristics in Table 1 is in line with the population distribution of Jinchuan [79]. As for intensity of air pollution (PAP1), Figure 2 shows that the majority $(62.1 \%)$ of the respondents perceived medium pollution ( 2 or 3 days a week), 18.3\% heavy pollution (4 or more days a week), and the rest (19.6\%) light pollution (0 or 1 days a week). The other indicators in Figure 2 measure perception of hazardousness as potential causes of health problems, specifically cardiovascular illnesses, respiratory illnesses and death (PAP2-PAP5). A five-point scale was used with 1 indicating weak perception and 5 indicating strong perception. Figure 2 shows that the vast majority (over $70 \%$ ) of the respondents perceived the pollution to be highly or moderately hazardous.

Figure 3 shows how knowledgeable the respondents are about Jinchuan's environment. For each statement a five-point scale ranging from 1 (strongly disagree) to 5 (strongly agree) was used. The first three statements (EK1-EK3) measure knowledge of general environmental issues in Jinchuan. As can be seen from Figure 3, the vast majority of the respondents strongly agree or agree that air pollution, industrial solid waste, and water pollution are serious environmental issues. With regard to the causes (measured by EK4), almost all of the respondents (93.2\%) acknowledge that local industries are the main source of Jinchuan's environmental problems. The last four statements (EK5-EK8) test the respondents' knowledge of the main air pollutants. The results show that chlorine gas is acknowledged as the main pollutant $(85.5 \%)$, followed by sulfur dioxide $(82.3 \%)$, suspended particles $(76 \%)$ and carbon dioxide $(57.9 \%)$.

\subsection{The Estimated SEM}

The hypothesized relationships in the Conceptual Model, summarized in Figure 1, are presented in Equation (4), the structural component of the SEM. It reads: 


$$
\left[\begin{array}{c}
\mathbf{P A P} \\
\mathbf{E K}
\end{array}\right]=\left[\begin{array}{cc}
0 & \beta_{12} \\
\beta_{21} & 0
\end{array}\right] \times\left[\begin{array}{c}
\mathbf{P A P} \\
\mathbf{E K}
\end{array}\right]+\left[\begin{array}{llllllll}
\gamma_{11} & \gamma_{12} & 0 & \gamma_{14} & \gamma_{15} & \gamma_{16} & \gamma_{17} & \gamma_{18} \\
\gamma_{21} & 0 & \gamma_{23} & 0 & \gamma_{2} & \gamma_{26} & \gamma_{27} & \gamma_{28}
\end{array}\right] \times\left[\begin{array}{c}
\mathbf{S E S} \\
\mathbf{F S} \\
\mathbf{A G E} \\
\mathbf{F H E} \\
\mathrm{MAP} \\
\mathrm{SAP} \\
\mathrm{NMS} \\
\mathrm{MS}
\end{array}\right]+\left[\begin{array}{l}
\zeta_{1} \\
\zeta_{2}
\end{array}\right]
$$

The measurement models, which are not given in Section 2, are presented in Equations (5) and (6):

$$
\left[\begin{array}{c}
\mathbf{P A P 1} \\
\vdots \\
\mathbf{P A P 5} \\
\mathbf{E K 1} \\
\vdots \\
\mathbf{E K 8}
\end{array}\right]=\left[\begin{array}{cc}
\lambda_{11}^{\mathrm{y}} & 0 \\
\lambda_{21}^{\mathrm{y}} & 0 \\
\vdots & \vdots \\
\lambda_{5}^{\mathrm{y}} & 0 \\
0 & \lambda_{62}^{\mathrm{y}} \\
0 & \lambda_{72}^{\mathrm{y}} \\
0 & \vdots \\
\vdots & \lambda_{132}^{\mathrm{y}} \\
0 &
\end{array}\right] \times\left[\begin{array}{c}
\mathbf{P A P} \\
\mathbf{E K}
\end{array}\right]+\left[\begin{array}{c}
\varepsilon_{1} \\
\vdots \\
\varepsilon_{5} \\
\varepsilon_{6} \\
\vdots \\
\varepsilon_{13}
\end{array}\right]
$$

$$
\left[\begin{array}{c}
\mathbf{E D U} \\
\mathbf{I N} \\
\mathbf{F S} \\
\mathbf{A G E} \\
\mathbf{F H E} \\
\text { MAP } \\
\text { SAP } \\
\text { NMS } \\
\text { MS }
\end{array}\right]=\left[\begin{array}{cc}
\lambda_{1}^{\mathrm{x}} & 0000000 \\
\lambda_{2}^{\mathrm{x}} & 0000000 \\
0 & 1000000 \\
0 & 0100000 \\
0 & 0010000 \\
0 & 0001000 \\
0 & 0000100 \\
0 & 0000010 \\
0 & 0000001
\end{array}\right] \times\left[\begin{array}{c}
\mathbf{S E S} \\
\mathbf{F S} \\
\mathbf{A G E} \\
\mathbf{F H E} \\
\mathrm{MAP} \\
\mathrm{SAP} \\
\mathrm{NMS} \\
\mathrm{MS}
\end{array}\right]+\left[\begin{array}{c}
\delta_{1} \\
\delta_{2} \\
0 \\
0 \\
0 \\
0 \\
0 \\
0
\end{array}\right]
$$

Note: To make the SEM identified and the parameters interpretable, the variances of the latent variables are fixed at 1 ; see [77] for details.

The dataset contains several ordinal and dichotomous variables, in particular, the indicators of PAP and EK. Moreover, the distributions of these indicators are highly skewed and non-normal (see Figures 2 and 3). For these reasons, the PAP-EK model was estimated by WLS based on the matrix of polychoric correlations [77].

First, the complete conceptual model, as specified in Equations (4)-(6) (denoted Initial model below) was estimated. The Initial model contained several insignificant variables. They were eliminated step-by-step where, at each step, the variable with the highest $p$-value was deleted. A path diagram of the Final model is presented in Figure 4.

Comparison of the overall goodness of fit statistics between the Initial and the Final model indicates whether the insignificant variables were correctly deleted. The overall goodness of fit statistics, presented in Table 2, are the Goodness-of-Fit Index(GFI), the $\chi^{2}$ /DF (DF denoting degrees of freedom), the Comparative Fit Index (CFI), the Incremental Fit Index (IFI), the Adjusted Goodness-of-Fit Index (AGFI) and the Root Mean Square Error of Approximation (RMSEA) (see $[77,80]$ for details). The almost negligible differences between the goodness of fit statistics of the Initial and Final model support the deletion of the insignificant variables. Particularly, GFI and AGFI are equal while the $\chi^{2} / \mathrm{DF}$, the RMSEA, IFI and CFI slightly improved.

Before turning to the estimated models, it should be noted that to facilitate comparison of coefficients (i.e., effects), standardized coefficients (beta coefficient) were estimated. A standardized coefficient represents the standard deviation change in the dependent variable for a one standard deviation change in the corresponding explanatory variable. Below the estimated measurement models are first discussed and then the structural model. 
The measurement models are shown in Table 3. It contains the standardized coefficients (loadings), standard errors and reliabilities $\left(\boldsymbol{R}^{2} \boldsymbol{s}\right)$, i.e., the proportion of variation of an indicator explained by its corresponding latent variables.

In the Initial model the indicator PAP1 has very low reliability (0.03) and its coefficient is substantially smaller than the coefficients of the other indicators (PAP2-PAP5). This is an indication that PAP1-PAP5 should not be taken as indicators of one underlying latent variable, PAP, but instead, that there are two latent perception variables: (i) Perceived intensity of air pollution (PAPL1); and (ii) Perceived hazardousness of air pollution (PAPL2). They are defined as the subjective assessment of the frequency of occurrence of heavy air pollution and of the hazardousness of the main air pollutants, respectively. To distinguish the latent variables from their indicators, " $\mathrm{L}$ " is added to their labels.

PAPL1 is identical to its sole indicator PAP1 whereas PAPL2 is measured by the indicators PAP2-PAP5. The distinction is in line with [44] who introduced the distinction and with [18] who further developed both dimensions and provided empirical evidence for the distinction. The partitioning of PAP into two separate latent variables is supported by the modification index of PAP1 as a possible indicator of PAPL2 which is very low (0.39). (The modification indices are available from the first author upon request.) Table 3 shows that PAP2-PAP5 are adequate indicators of the latent variable PAPL2 with significant loadings and satisfactory reliabilities. The table furthermore shows that the indicators of the latent variables EK and SES in the Final model significantly load on their corresponding latent variables and that the reliabilities are satisfactory.

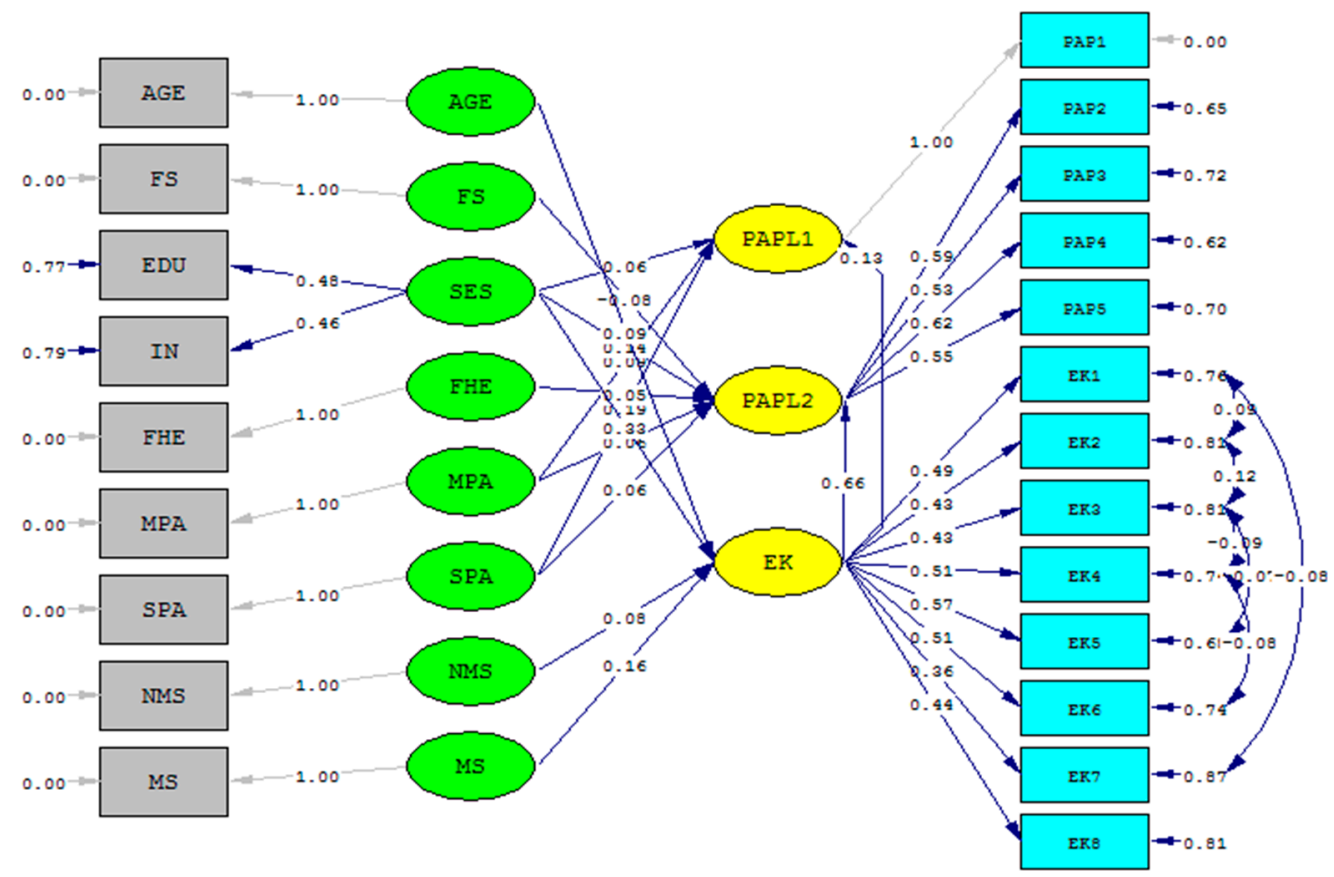

Figure 4. Path diagram of the Final model.

Table 2. Overall goodness of fit indices.

\begin{tabular}{cccc}
\hline Fit Index & Initial Model & Final Model & Cut off Value \\
\hline Goodness-of-Fit Index (GFI) & 0.98 & 0.98 & $>0.90$ \\
$\chi^{2}$ /DF & 2.53 & 2.47 & $<3.00$ \\
Comparative Fit Index (CFI) & 0.91 & 0.93 & $>0.90$ \\
Incremental Fit Index (IFI) & 0.92 & 0.93 & $>0.90$ \\
Adjusted Goodness-of-Fit Index (AGFI) & 0.97 & 0.97 & $>0.80$ \\
Root Mean Square Error of Approximation (RMSEA) & 0.045 & 0.041 & $<0.05$ \\
\hline
\end{tabular}


Table 3. The measurement models (standardized coefficients)

\begin{tabular}{|c|c|c|c|c|c|c|c|c|c|}
\hline \multirow{2}{*}{ Latent Variables } & \multicolumn{4}{|c|}{ Final Model } & \multirow{2}{*}{ Latent Variables } & \multicolumn{4}{|c|}{ Initial Model } \\
\hline & Indicators & Coefficient & Standard Errors & $R^{2}$ & & Indicators & Coefficient & Standard Errors & $R^{2}$ \\
\hline $\begin{array}{l}\text { Perceived intensity of } \\
\text { pollution (PAPL1) }\end{array}$ & PAP1 & 1.00 & - & 1.00 & \multirow{5}{*}{$\begin{array}{l}\text { Perception of air } \\
\text { pollution (PAP) }\end{array}$} & PAP1 & 0.16 & 0.05 & 0.03 \\
\hline \multirow{4}{*}{$\begin{array}{l}\text { Perceived hazardousness of the } \\
\text { pollutants (PAPL2) }\end{array}$} & PAP2 & 0.59 & 0.03 & 0.35 & & PAP2 & 0.60 & 0.04 & 0.35 \\
\hline & PAP3 & 0.53 & 0.03 & 0.28 & & PAP3 & 0.53 & 0.05 & 0.28 \\
\hline & PAP4 & 0.62 & 0.03 & 0.38 & & PAP4 & 0.62 & 0.04 & 0.38 \\
\hline & PAP5 & 0.55 & 0.03 & 0.30 & & PAP5 & 0.55 & 0.05 & 0.30 \\
\hline \multirow{8}{*}{ Environmental knowledge (EK) } & EK1 & 0.49 & 0.04 & 0.24 & \multirow{8}{*}{$\begin{array}{l}\text { Environmental } \\
\text { knowledge (EK) }\end{array}$} & EK1 & 0.49 & 0.06 & 0.24 \\
\hline & EK2 & 0.43 & 0.04 & 0.19 & & EK2 & 0.43 & 0.06 & 0.19 \\
\hline & EK3 & 0.43 & 0.04 & 0.19 & & EK3 & 0.43 & 0.07 & 0.19 \\
\hline & EK4 & 0.51 & 0.03 & 0.25 & & EK4 & 0.50 & 0.07 & 0.25 \\
\hline & EK5 & 0.57 & 0.04 & 0.32 & & EK5 & 0.57 & 0.07 & 0.32 \\
\hline & EK5 & 0.51 & 0.03 & 0.26 & & EK5 & 0.51 & 0.07 & 0.26 \\
\hline & EK7 & 0.36 & 0.03 & 0.13 & & EK7 & 0.36 & 0.07 & 0.13 \\
\hline & EK8 & 0.44 & 0.03 & 0.19 & & EK8 & 0.44 & 0.07 & 0.19 \\
\hline \multirow{2}{*}{ Socio-economic status (SES) } & Education & 0.48 & 0.05 & 0.23 & \multirow{2}{*}{$\begin{array}{l}\text { Socio-economic } \\
\text { status (SES) }\end{array}$} & Education & 0.45 & 0.05 & 0.21 \\
\hline & Income & 0.46 & 0.04 & 0.21 & & Income & 0.46 & 0.04 & 0.21 \\
\hline
\end{tabular}


Table 4 shows the structural model. It presents the standardized coefficients, standard errors and $R^{2} s$. As hypothesized in the conceptual model, EK has a positive and significant impact on PAPL1 (0.13) and PAPL2 (0.66), respectively. However, the reverse effect (0.22) was not significant in the Initial model and therefore was deleted. A possible explanation for the insignificance is that the suffocating and pungent odor of sulfur dioxide and chlorine gas, which are the main directly observed air pollutants in the area, is sufficient evidence of air pollution. The persistence of the odor renders further knowledge acquisition redundant. Furthermore, the insignificance of both perception variables on EK indicates absence of self-confirmation bias, as there is no evidence for the first step specified in Section 2. In the Initial model the distance effect (MAP (-0.02) and SAP (0.05)) is highly insignificant which is in line with [63]. Therefore these variables are not considered in the Final model.

Table 4. The structural model (standardized coefficients).

\begin{tabular}{|c|c|c|c|c|c|}
\hline \multirow{2}{*}{ Variables } & \multicolumn{3}{|c|}{ Final Model } & \multicolumn{2}{|c|}{ Initial Model } \\
\hline & EK & PAPL1 & PAPL2 & EK & PAP \\
\hline Perception of air pollution (PAP) & & & & $\begin{array}{c}0.22 \\
(0.23)\end{array}$ & \\
\hline Environmental knowledge(EK) & & $\begin{array}{l}0.13^{* * *} \\
(0.04)\end{array}$ & $\begin{array}{l}0.66^{* * *} \\
(0.08)\end{array}$ & & $\begin{array}{c}0.50^{* * *} \\
(0.30)\end{array}$ \\
\hline Socio-economic status (SES) & $\begin{array}{l}0.33^{* * *} \\
(0.07)\end{array}$ & $\begin{array}{c}0.06 \\
(0.05)\end{array}$ & $\begin{array}{l}0.14^{* * *} \\
(0.08)\end{array}$ & $\begin{array}{l}0.22 * * * \\
(0.11)\end{array}$ & $\begin{array}{c}0.29 * * * \\
(0.10)\end{array}$ \\
\hline Age(AGE) & $\begin{array}{c}0.09 * * * \\
0.03\end{array}$ & & & $\begin{array}{c}0.08^{* *} \\
(0.03)\end{array}$ & \\
\hline Family size (FS) & & & $\begin{array}{l}-0.08^{* * *} \\
(0.03)\end{array}$ & & $\begin{array}{l}-0.09 * * * \\
(0.03)\end{array}$ \\
\hline Family health experience (FHE) & & & $\begin{array}{l}0.05^{*} \\
(0.03)\end{array}$ & & $\begin{array}{l}0.06^{* *} \\
(0.03)\end{array}$ \\
\hline Medium air pollution (MAP) & & $\begin{array}{l}0.09^{* * *} \\
(0.03)\end{array}$ & $\begin{array}{c}0.06 \\
(0.04)\end{array}$ & $\begin{array}{l}-0.02 \\
(0.04)\end{array}$ & $\begin{array}{l}0.08^{*} \\
(0.04)\end{array}$ \\
\hline Serious air pollution (SAP) & & $\begin{array}{l}0.19^{* * *} \\
(0.03)\end{array}$ & $\begin{array}{c}0.06 \\
(0.04)\end{array}$ & $\begin{array}{c}0.05 \\
(0.04)\end{array}$ & $\begin{array}{l}0.09 * * \\
(0.04)\end{array}$ \\
\hline $\begin{array}{l}\text { JMC employee, but not miner or } \\
\text { smelter worker (NMS) }\end{array}$ & $\begin{array}{c}0.08 \\
(0.05)\end{array}$ & & & $\begin{array}{c}0.06 \\
(0.05)\end{array}$ & $\begin{array}{l}-0.03 \\
(0.05)\end{array}$ \\
\hline Miner or smelter worker of JMC (MS) & $\begin{array}{c}0.16^{* * *} \\
(0.04)\end{array}$ & & & $\begin{array}{l}0.12 * * \\
(0.05)\end{array}$ & $\begin{array}{c}0.02 \\
(0.06)\end{array}$ \\
\hline$R^{2}$ & 0.13 & 0.05 & 0.51 & 0.19 & 0.37 \\
\hline
\end{tabular}

Note: Standard errors in parenthesis. ${ }^{*}, * *$ and ${ }^{* * *}: 10 \%, 5 \%$ and $1 \%$, respectively.

The discussion below is primarily based on the Final model. The exogenous variables of EK are discussed first and next those of PAPL1 and PAPL2. The Final model shows that SES positively and significantly influences EK (0.33), which is in line with [67-69]. As in [62], Age has a positive and significant impact (0.09) on EK indicating that living longer in Jinchuan increases knowledge about its mining and smelting industries and related environmental issues. WE, measured by the dummies MS (miners and smelter workers) and NMS (JMC employees, but not miners or smelter workers) with non-JMC individuals as the reference case is also an important determinant of EK. The impacts are 0.16 and 0.08 , respectively. Apparently, miners and smelter workers of the mining company have better knowledge of Jinchuan's environmental issues than the non-JMC employees. This result is in line with $[32,64]$.

The main results regarding the perception variables are as follows. In addition to its indirect effect via EK, SES directly and significantly impacts PAPL2 (0.14). Its direct impact (0.06) on PAPL1 is also positive, though marginally significant. The difference in impacts on PAPL2 and PAPL1 is probably caused by the fact that intensity is more easily observable than hazardousness of pollutants which requires acquisition and processing of information. FS has a negative impact $(-0.08)$ on PAPL2 which 
is in contrast to the Conceptual model. A possible explanation is that perception of air pollution per se is linked to risk perception. Larger families have larger social networks, which offers opportunities for burden sharing [81,82] via cooperation or the use of shared resources [83,84]. FHE has a positive impact (0.05) on PAPL2, as hypothesized in the Conceptual model. This result is in line with [38,74]. As expected, and in line with [1,85], living in severely and moderately polluted areas increases both PAPL1 (MAP (0.09) and SAP (0.19)) and PAPL2 (MAP (0.06) and SAP (0.06)), although the latter impact is marginally significant. Finally, in the Initial model, the impact of WE on PAP (NMS $(-0.03)$ and MS (0.06)) was insignificant. This could be because of employment dependency, which tends to mask the negative impacts of variables such as WE [73]. Since no significant WE effect was discerned in the Initial model, WE was not included in the PAPL1 and PAPL2 equations in the Final model.

Table 5 presents the standardized total and indirect effects of all (endogenous and exogenous) variables on all endogenous variables in the Final model. An indirect effect represents the effect of a variable on another variable through intervening endogenous variables [77]. The total effect is the sum of the direct and indirect effects. Table 5 shows that serious air pollution (SAP), EK, SES and medium air pollution (MAP) are the four most important predictors of PAPL1 with total effects of $0.19,0.13,0.10$, and 0.09 , respectively. Age, mine and smelter workers (MS) and other JMC employees (NMS) also positively influence PAPL1 with total effects of 0.01, 0.01 and 0.02, respectively. The effect of NMS, however, is not significant.

Table 5. Standardized total and indirect effects (Final model).

\begin{tabular}{|c|c|c|c|c|c|c|}
\hline \multirow{2}{*}{ Variables } & \multicolumn{3}{|c|}{ Indirect Effect } & \multicolumn{3}{|c|}{ Total Effect } \\
\hline & EK & PAPL1 & PAPL2 & EK & PAPL1 & PAPL2 \\
\hline Environmental knowledge (EK) & & & & & $\begin{array}{l}0.13^{* * *} \\
(0.04)\end{array}$ & $\begin{array}{c}0.66^{* * *} \\
(0.08)\end{array}$ \\
\hline Family size (FS) & & & & & & $\begin{aligned}-0.08^{* * * *} & (0.03)\end{aligned}$ \\
\hline Age (AGE) & & $\begin{array}{l}0.01 * * \\
(0.01)\end{array}$ & $\begin{array}{l}0.06^{* * *} \\
(0.02)\end{array}$ & $\begin{array}{l}0.09^{* * *} \\
(0.01)\end{array}$ & $\begin{array}{l}0.01 * * \\
(0.02)\end{array}$ & $\begin{array}{c}0.06^{* * *} \\
(0.03)\end{array}$ \\
\hline Socio-economic status (SES) & & $\begin{array}{l}0.04^{* * *} \\
(0.02)\end{array}$ & $\begin{array}{l}0.02^{* * *} \\
(0.06)\end{array}$ & $\begin{array}{c}0.33^{* * *} \\
(0.07)\end{array}$ & $\begin{array}{l}0.10^{* * *} \\
(0.05)\end{array}$ & $\begin{array}{c}0.35^{* * *} \\
(0.09)\end{array}$ \\
\hline Family health experience (FHE) & & & & & & $\begin{array}{l}0.05^{*} \\
(0.03)\end{array}$ \\
\hline Medium air pollution (MAP) & & & & & $\begin{array}{l}0.09 * * * \\
(0.03)\end{array}$ & $\begin{array}{c}0.06 \\
(0.04)\end{array}$ \\
\hline Serious air pollution (SAP) & & & & & $\begin{array}{c}0.19^{* * *} \\
(0.03)\end{array}$ & $\begin{array}{c}0.06 \\
(0.04)\end{array}$ \\
\hline $\begin{array}{l}\text { JMC employee, but not miner or } \\
\text { smelter worker (NMS) }\end{array}$ & & $\begin{array}{c}0.01 \\
(0.01)\end{array}$ & $\begin{array}{c}0.05 \\
(0.04)\end{array}$ & $\begin{array}{c}0.08 \\
(0.05)\end{array}$ & $\begin{array}{c}0.01 \\
(0.01)\end{array}$ & $\begin{array}{c}0.05 \\
(0.04)\end{array}$ \\
\hline Miner or smelter worker of JMC (MS) & & $\begin{array}{l}0.02 * * \\
(0.01)\end{array}$ & $\begin{array}{l}0.10^{* * *} \\
(0.03)\end{array}$ & $\begin{array}{c}0.16^{* * *} \\
(0.04)\end{array}$ & $\begin{array}{l}0.02 * * \\
(0.01)\end{array}$ & $\begin{array}{l}0.10^{* * *} \\
(0.04)\end{array}$ \\
\hline
\end{tabular}

Note: Standard errors in parenthesis. ${ }^{*}, * *$ and ${ }^{* *}: 10 \%, 5 \%$ and $1 \%$, respectively.

Table 5 furthermore shows that EK has the largest positive total effect (0.66) on PAPL2, followed by SES with a total effect of 0.35 . Age and FHE also positively and significantly influence PAPL2 with total effects of 0.06 and 0.05 , respectively. FS negatively and significantly influences PAPL2 with a total effect of -0.08 . Although they have no direct effects on PAPL2, NMS and MS positively influence it through EK, with total effects of 0.05 and 0.10, respectively. The effect of NMS, however, is not significant.

SES is the most important determinant of EK with a total effect of 0.33 . NMS and MS positively impact EK, but only MS is significant with a total effect of 0.16. Next is Age (0.09). 


\section{Discussion}

In this paper, a structural equation model (SEM) was applied to analyze perception of air pollution in the Jinchuan mining area, Gansu Province, China, based on a cross-sectional sample of 759 respondents. To the best of the authors' knowledge, this is the first paper to address this issue in China.

The literature on air pollution does usually not distinguish between the perception of the occurrence of air pollution and the perception of the probability of suffering from an illness caused by exposure to it (risk perception). However, ignoring the difference may lead to loss of information and biased estimation results. The distinction between both types of perception is also relevant for educational campaigns aimed at stimulating averting behavior. Adequate campaigns should target the right kind of perception.

It was shown that there are two types of perception: perceived intensity and perceived hazardousness of the pollutants. Both types are influenced by environmental knowledge. However, there are no reverse effects from perception to environmental knowledge. The first type of perception is furthermore influenced by socio-economic status and proximity to the pollution source; the latter by socio-economic status, family health experience, family size and proximity to the pollution source. Environmental knowledge is influenced by socio-economic status, age and work environment.

The main finding is that virtually all respondents $(97.8 \%)$ acknowledged that Jinchuan's air is heavily polluted. In particular, more than $70 \%$ perceived high intensity and hazardousness of air pollution despite the fact that public information on air pollution and its health impacts is not freely available. Since environmental knowledge positively impacts on the perception of air pollution, information on air quality should be widely disclosed to enable the residents to take action to reduce exposure and health risks. This applies especially to young people and those with low education who have limited knowledge. Furthermore, even though people may be knowledgeable of air pollution in the region in general, they may be unable to collect information about its day-to-day severity. Therefore, in combination with the weather forecast, information on local air quality conditions could be communicated and risk mitigating actions such as reducing or abandoning outdoor activities could be recommended. The finding that environmental knowledge among older age groups is better than among younger people implies that more attention should be paid to young people's environmental education, e.g., in middle school.

\section{Conclusions}

The results of our study can help policymakers of Jinchuan mining area better understand the need for pollution information disclosure and education programs aimed at making local residents aware of air pollution and related health risks and enhancing their personal responses in reducing exposure to air pollutants.

The present study is possibly the first on environmental knowledge and perception of air pollution in China, no prior information on measurement of these latent variables was available. Therefore, the indicators developed and tested here had not been tested before. Further development and testing of indicators of environmental knowledge and perception of air pollution is urgently needed, especially in the light of the alarming state of the environment in many Chinese cities. However, this kind of scientific research has a substantially wider application than just China because most cities in most developing countries are suffering from similar problems. The present paper could be a starting point for further theoretical and empirical research on the interaction between environmental knowledge and the perception of air pollution but also of other kinds of pollution in China. It could also stimulate similar research in other developing countries, in Western countries and be used for cross-national or cross-cultural comparisons. This study has also introduced notions that could be applied in studies on the perception of the probability of suffering from an illness and in averting behavior studies. 
Acknowledgments: We gratefully acknowledge the comments and suggestions by three anonymous reviewers and by the Academic Editor, Kim Natasha Dirks which have helped us improve previous versions of the paper. The usual disclaimer applies.

Author Contributions: Zhengtao Li, Henk Folmer and Jianhong Xue conceived and designed the research questions, the conceptual model, the questionnaire and the methodology; Zhengtao Li collected and analyzed the data; Zhengtao Li, Henk Folmer and Jianhong Xue wrote the paper.

Conflicts of Interest: The authors declare no conflict of interest.

\section{References}

1. Bickerstaff, K.; Walker, G. Public understandings of air pollution: The "localization" of environmental risk. Glob. Environ. Chang. 2001, 11, 133-145. [CrossRef]

2. Leem, J.H.; Kaplan, B.M.; Shim, Y.K.; Pohl, H.R.; Gotway, C.A.; Bullard, S.M.; Rogers, J.F.; Smith, M.M.; Tylenda, C.A. Exposures to air pollutants during pregnancy and preterm delivery. Environ. Health Perspect. 2006, 114, 905-910. [CrossRef] [PubMed]

3. WHO (World Health Organization). Evidence on Health Aspects of Air Pollution to Review EU Policies-The REVIHAAP Project; Technical Report; WHO Regional Office for Europe: Copenhagen, Denmark, 2013.

4. Woodruff, R.B. Customer value: The next source for competitive advantage. J. Acad. Mark. Sci. 1997, 25, 139-153. [CrossRef]

5. Glinianaia, S.V.; Rankin, J.; Bell, R.; Pless-Mulloli, T.; Howel, D. Particulate air pollution and fetal health: A systematic review of the epidemiologic evidence. Epidemiology 2004, 15, 36-45. [CrossRef] [PubMed]

6. Hoek, E.; Carranza-Torres, C.; Corkum, B. Hoek-Brown Failure Criterion-2002 Edition. Available online: https://www.eoas.ubc.ca/courses/eosc433/lecture-material/H-B\%20Criterion $\% 20 \% 282002 \%$ 20Hoek\%29.pdf (accessed on 15 February 2016).

7. Jerrett, M.; Burnett, R.T.; Ma, R.; Pope, C.A., III; Krewski, D.; Newbold, K.B.; Thurston, G.; Shi, Y.; Finkelstein, N.; Calle, E.E.; et al. Spatial analysis of air pollution and mortality in Los Angeles. Epidemiology 2005, 16, 727-736. [CrossRef] [PubMed]

8. Beeson, W.L.; Abbey, D.E.; Knutsen, S.F. Long-term concentrations of ambient air pollutants and incident lung cancer in California adults: Results from the AHSMOG study. Adventist Health Study on Smog. Environ. Health Perspect. 1998, 106, 813-822. [CrossRef] [PubMed]

9. Tseng, C.Y.; Huang, Y.C.; Su, S.Y.; Huang, J.Y.; Lai, C.H.; Lung, C.C.; Ho, C.C.; Liaw, Y.P. Cell type specificity of female lung cancer associated with sulfur dioxide from air pollutants in Taiwan: An ecological study. BMC Public Health 2012, 12, 4. [CrossRef] [PubMed]

10. Pope, C.A., III. Mortality effects of longer term exposures to fine particulate air pollution: Review of recent epidemiological evidence. Inhal. Toxicol. 2007, 19 (Suppl. S1), 33-38. [CrossRef] [PubMed]

11. Pao, H.T.; Fu, H.C.; Tseng, C.L. Forecasting of $\mathrm{CO}_{2}$ emissions, energy consumption and economic growth in China using an improved grey model. Energy 2012, 40, 400-409. [CrossRef]

12. Parker, J.D.; Woodruff, T.J. Influences of study design and location on the relationship between particulate matter air pollution and birthweight. Paediatr. Perinat. Epidemiol. 2008, 22, 214-227. [CrossRef] [PubMed]

13. Wang, S.; Hao, J. Air quality management in China: Issues, challenges, and options. J. Environ. Sci. 2012, 24, 2-13. [CrossRef]

14. Zhang, L.W.; Chen, X.; Xue, X.D.; Sun, M.; Han, B.; Li, C.P.; Ma, J.; Yu, H.; Zhao, L.J.; Zhao, B.X.; et al. Long-term exposure to high particulate matter pollution and cardiovascular mortality: A 12-year cohort study in four cities in northern China. Environ. Int. 2014, 62, 41-47. [CrossRef] [PubMed]

15. Wei, K. Analysis of Atmosphere Sulfur Dioxide Pollution Control and Countermeasures; Lanzhou University: Lanzhou, China, 2008. (In Chinese)

16. Li, T.; Zhao, Y. The distribution and pollution analysis of the heavy metal $\mathrm{Ni}, \mathrm{Cu}, \mathrm{Pb}, \mathrm{Cd}$, in Jinchuan. China Environ. Manag. 2004, 2, 52-53. (In Chinese)

17. Huang, H.; Nan, Z.; Hu, X.; Liu, X.; Li, Y.; Ding, H. Spatial distributions of heavy metals and assessment of potential ecological risk in Jinchang urban area. Adm. Technol. Environ. Monit. 2009, 5, 7-10.

18. Egondi, T.; Kyobutungi, C.; Ng, N.; Muindi, K.; Oti, S.; van de Vijver, S.; Ettarh, R.; Rocklöv, J. Community perceptions of air pollution and related health risks in Nairobi Slums. Int. J. Environ. Res. Public Health 2013, 10, 4851-4868. [CrossRef] [PubMed] 
19. Folmer, H.; Johansson-Stenman, O. Does environmental economics produce aero-planes without engines? On the need for an environmental social science. Environ. Resour. Econ. 2011, 48, 337-361. [CrossRef]

20. Folmer, H. Why sociology is better conditioned to explain economic behaviour than economics. Kyklos 2009, 62, 258-274. [CrossRef]

21. Riddel, M.; Shaw, W.D. A theoretically-consistent empirical model of non-expected utility: An application to nuclear-waste transport. J. Risk Uncertain. 2006, 32, 131-150. [CrossRef]

22. Shaw, W.D.; Woodward, R.T. Why environmental and resource economists should care about non-expected utility models. Resour. Energy Econ. 2008, 30, 66-89. [CrossRef]

23. Hampton, J.M.; Moore, P.G.; Thomas, H. Subjective probability and its measurement. J. R. Stat. Soc. 1973, 136, 21-42. [CrossRef]

24. Freudenstein, F.; Wiedemann, P.M.; Varsier, N. Exposure knowledge and risk perception of RF EMF. Front. Public Health 2015, 2, 289. [CrossRef] [PubMed]

25. Claeson, A.S.; Lidén, E.; Nordin, M.; Nordin, S. The role of perceived pollution and health risk perception in annoyance and health symptoms: A population-based study of odorous air pollution. Int. Arch. Occup. Environ. Health 2013, 86, 367-374. [CrossRef] [PubMed]

26. Saksena, S. Public perceptions of urban air pollution risks. Risk Hazards Crisis Public Policy 2011, 2, 1-19. [CrossRef]

27. Liu, X.; Anbumozhi, V. Determinant factors of corporate environmental information disclosure: An empirical study of Chinese listed companies. J. Clean. Prod. 2009, 17, 593-600. [CrossRef]

28. Riley, T.; Cai, H. Unmasking Chinese business enterprises: Using information disclosure laws to enhance public participation in corporate environmental decision making. Harv. Environ. Law Rev. 2009, 33, 177-224.

29. Guo, P. Corporate Environmental Reporting and Disclosure in China; CSR Asia: Beijing, China, 2005.

30. Xu, J.; Meng, F. Environmental Accounting 164; Shanghai Finance University Press: Shanghai, China, 2004.

31. Shavit, T.; Shahrabani, S.; Benzion, U.; Rosenboim, M. The effect of a forest fire disaster on emotions and perceptions of risk: A field study after the Carmel fire. J. Environ. Psychol. 2013, 36, 129-135. [CrossRef]

32. Doria Mde, F.; Pidgeon, N.; Hunter, P.R. Perceptions of drinking water quality and risk and its effect on behaviour: A cross-national study. Sci. Total Environ. 2009, 407, 5455-5464. [CrossRef] [PubMed]

33. Arcury, T.A.; Quandt, S.A.; Russell, G.B. Pesticide safety among farmworkers: Perceived risk and perceived control as factors reflecting environmental justice. Environ. Health Perspect. 2002, 110 (Suppl. S2), 233-240. [CrossRef] [PubMed]

34. Robinson, K.G.; Robinson, C.H.; Raup, L.A.; Markum, T.R. Public attitudes and risk perception toward land application of biosolids within the south-eastern United States. J. Environ. Manag. 2012, 98, 29-36. [CrossRef] [PubMed]

35. Lai, C.-L.; Tao, J. Perception of environmental hazards in Hong Kong Chinese. Risk Anal. 2003, 23, 669-684. [PubMed]

36. Zhu, D.; Xie, X.; Gan, Y. Information source and valence: How information credibility influences earthquake risk perception. J. Environ. Psychol. 2011, 31, 129-136. [CrossRef]

37. Venables, D.; Pidgeon, N.F.; Parkhill, K.A.; Henwood, K.L.; Simmons, P. Living with nuclear power: Sense of place, proximity, and risk perceptions in local host communities. J. Environ. Psychol. 2012, 32, 371-383. [CrossRef]

38. Howel, D.; Moffatt, S.; Bush, J.; Dunn, C.E.; Prince, H. Public views on the links between air pollution and health in Northeast England. Environ. Res. 2003, 91, 163-171. [CrossRef]

39. Elliott, S.J.; Cole, D.C.; Krueger, P.; Voorberg, N.; Wakefield, S. The power of perception: Health risk attributed to air pollution in an urban industrial neighbourhood. Risk Anal. 1999, 19, 621-634. [CrossRef] [PubMed]

40. Catalán-Vázquez, M.; Schilmann, A.; Riojas-Rodríguez, H. Perceived health risks of manganese in the Molango mining district, Mexico. Risk Anal. 2010, 30, 619-634. [CrossRef] [PubMed]

41. Omanga, E.; Ulmer, L.; Berhane, Z.; Gatari, M. Industrial air pollution in rural Kenya: Community awareness, risk perception and associations between risk variables. BMC Public Health 2014, 14, 377. [CrossRef] [PubMed]

42. Richardson, L.A.; Champ, P.A.; Loomis, J.B. The hidden cost of wildfires: Economic valuation of health effects of wildfire smoke exposure in Southern California. J. For. Econ. 2012, 18, 14-35. [CrossRef]

43. Gregory, F.H. Soft systems models for knowledge elicitation and representation. J. Oper. Res. Soc. 1995, 46, 562-578. [CrossRef] 
44. Sjöberg, L.; Moen, B.-E.; Rundmo, T. Explaining Risk Perception. An Evaluation of the Psychometric Paradigm in Risk Perception Research; Rotunde Publikasjoner: Trondheim, Norway, 2004.

45. Spearman, C. “General Intelligence”, objectively determined and measured. Am. J. Psychol. 1904, 15, $201-292$. [CrossRef]

46. Kmenta, J. Latent Variables. In Elements of Econometrics, 2nd ed.; Macmillan: New York, NY, USA, 1986; pp. 581-587.

47. Borsboom, D.; Mellenbergh, G.J.; Van Heerden, J. The theoretical status of latent variables. Psychol. Rev. 2003, 110, 203-219. [CrossRef] [PubMed]

48. Greene, J.A.; Brown, S.C. The wisdom development scale: Further validity investigations. Int. J. Aging Hum. Dev. 2009, 68, 289-320. [CrossRef] [PubMed]

49. Berkes, F.; Colding, J.; Folke, C. Rediscovery of traditional ecological knowledge as adaptive management. Ecol. Appl. 2000, 10, 1251-1262. [CrossRef]

50. De Lavega, E.L. Awareness, Knowledge, and Attitude about Environmental Education: Responses from Environmental Specialists, High School Instructors, Students, and Parents. Ph.D. Thesis, University of Central Florida, Orlando, FL, USA, 2004.

51. Madsen, P. What can universities and professional schools do to save the environment. In Earth Summit Ethics: Toward a Reconstructive Postmodern Philosophy of Environmental Education; Albany State University of New York Press: Albany, NY, USA, 1996; pp. 71-91.

52. Freire, P. Education: Domestication or liberation? Prospects 1972, 2, 173-181. [CrossRef]

53. Boud, D.; Miller, N. Working with Experience: Animating Learning; Routledge: London, UK, 1996.

54. Raghubir, P.; Menon, G. Aids and me, never the twain shall meet: The effects of information accessibility on judgments of risk and advertising effectiveness. J. Consum. Res. 1998, 25, 52-63. [CrossRef]

55. Bernardi, L. Determinants of individual aids risk perception: Knowledge, behavioural control and social influence. Afr. J. AIDS Res. 2002, 1, 111-124. [CrossRef] [PubMed]

56. Wilson, C.; Evans, G.; Leppard, P.; Syrette, J. Reactions to genetically modified food crops and how perception of risks and benefits influences consumers' information gathering. Risk Anal. 2004, 24, 1311-1321. [CrossRef] [PubMed]

57. Rock, I. Perception and knowledge. Acta Psychol. 1985, 59, 3-22. [CrossRef]

58. Hopp, W. Perception and Knowledge: A Phenomenological Account; Cambridge University Press: New York, NY, USA, 2011.

59. Cross, F.B.; Prentice, R.A. Law and Corporate Finance; Edward Elgar Publishing: Cheltenham, UK, 2007.

60. Davies, P.; Drive, T. Tuberculosis: No Longer Down and Out. Available online: http://www.priory.com/ med/tubercul.htm (accessed on 15 February 2016).

61. Aminrad, Z.; Zakaria, S.Z.B.S.; Hadi, A.S. Influence of age and level of education on environmental awareness and attitude: Case study on Iranian students in Malaysian universities. Soc. Sci. 2011, 6, 15-19. [CrossRef]

62. Al Khamees, N.A.; Alamari, H. Knowledge of, and attitudes to, indoor air pollution in Kuwaiti students, teachers and university faculty. Coll. Stud. J. 2009, 43, 1306-1312.

63. Mirzaei, R.; Alireza, A.; Mahdi, M.; Fatemeh, R.; Maryam, S. Noise pollution in Zahedan and residents' knowledge about noise pollution. J. Health Scope 2012, 1, 3-6. [CrossRef]

64. Juang, D.; Lee, C.; Yang, T.; Chang, M. Noise pollution and its effects on medical care workers and patients in hospitals. Int. J. Environ. Sci. Technol. 2010, 7, 705-716. [CrossRef]

65. Rundmo, T. Perceived risk, safety status, and job stress among injured and noninjured employees on offshore petroleum installations. J. Saf. Res. 1995, 26, 87-97. [CrossRef]

66. Bradley, R.H.; Corwyn, R.F. Socioeconomic status and child development. Annu. Rev. Psychol. 2002, 53, 371-399. [CrossRef] [PubMed]

67. Diamantopoulos, A.; Schlegelmilch, B.B.; Sinkovics, R.R.; Bohlen, G.M. Can socio-demographics still play a role in profiling green consumers? A review of the evidence and an empirical investigation. J. Bus. Res. 2003, 56, 465-480. [CrossRef]

68. Ogunbode, C.A.; Arnold, K. A study of environmental awareness and attitudes in Ibadan, Nigeria. Hum. Ecol. Risk Assess. Int. J. 2012, 18, 669-684. [CrossRef]

69. Abreu, M.; Lins, J. A demographic analysis of consumer environmental attitudes about liquefied petroleum gas in Brazil. Electron. J. Bus. Ethics Organ. Stud. 2010, 15, 6-14. 
70. Badland, H.M.; Duncan, M.J. Perceptions of air pollution during the work-related commute by adults in Queensland, Australia. Atmos. Environ. 2009, 43, 5791-5795. [CrossRef]

71. Khan, D.A.; Shabbir, S.; Majid, M.; Naqvi, T.A.; Khan, F.A. Risk assessment of pesticide exposure on health of pakistani tobacco farmers. J. Expo. Sci. Environ. Epidemiol. 2009, 20, 196-204. [CrossRef] [PubMed]

72. Ndunda, E.N.; Mungatana, E.D. Farmers' perception and knowledge of health risks in wastewater irrigation. Open Sci. Repos. Nat. Resour. Conserv. 2013. [CrossRef]

73. Lee, D.S.; Chiu, M.; Manuel, D.G.; Tu, K.; Wang, X.; Austin, P.C.; Mattern, M.Y.; Mitiku, T.F.; Svenson, L.W.; Putnam, W.; et al. Trends in risk factors for cardiovascular disease in Canada: Temporal, socio-demographic and geographic factors. Can. Med. Assoc. J. 2009, 181, E55-E66. [CrossRef] [PubMed]

74. Njagi, J.; Ireri, A.; Njagi, E.; Akunga, D.; Afullo, A.; Ngugi, M.; Mwanzo, I.; Njagi, I. Knowledge, attitude and perceptions of village residents on the health risks posed by kadhodeki dumpsite in Nairobi, Kenya. Ethiop. J. Environ. Stud. Manag. 2013. [CrossRef]

75. Bickerstaff, K.; Walker, G. Clearing the smog? Public responses to air-quality information. Local Environ. 1999, 4, 279-294. [CrossRef]

76. Särndal, C.E.; Swensson, B.; Wretman, J. Model Assisted Survey Sampling; Springer Science \& Business Media: New York, NY, USA, 2003.

77. Jöreskog, K.G.; Sörbom, D. LISREL 8: User's Reference Guide; Scientific Software International: Lincolnwood, IL, USA, 1996.

78. Oud, J.H.; Folmer, H. A structural equation approach to models with spatial dependence. Geogr. Anal. 2008, 40, 152-166. [CrossRef]

79. Jinchuan Statistical Yearbook. Statistical Yearbook; Jinchuan Statistic Bureau: Jinchuan, China, 2010. (In Chinese)

80. Ouyang, Y. The mediating effects of job stress and job involvement under job instability: Banking service personnel of Taiwan as an example. J. Money Investig. Bank. 2009, 11, 16-26.

81. Koehly, L.M.; Peters, J.A.; Kuhn, N.; Hoskins, L.; Letocha, A.; Kenen, R.; Loud, J.; Greene, M.H. Sisters in hereditary breast and ovarian cancer families: Communal coping, social integration, and psychological well-being. Psycho-Oncology 2008, 17, 812-821. [CrossRef] [PubMed]

82. Gorman, B.K.; Sivaganesan, A. The role of social support and integration for understanding socioeconomic disparities in self-rated health and hypertension. Soc. Sci. Med. 2007, 65, 958-975. [CrossRef] [PubMed]

83. Lyons, R.F.; Mickelson, K.D.; Sullivan, M.J.; Coyne, J.C. Coping as a communal process. J. Soc. Person. Relatsh. 1998, 15, 579-605. [CrossRef]

84. Hobfoll, S.E.; Schröder, K.E.E.; Wells, M.; Malek, M. Communal versus individualistic construction of sense of mastery in facing life challenges. J. Soc. Clin. Psychol. 2002, 21, 362-399. [CrossRef]

85. Riddel, M. Risk perception, ambiguity, and nuclear-waste transport. South. Econ. J. 2009, 75, 781-797. 